\title{
Okul Öncesi Öğrencilerinin Programın Kazanımlarına Ulaşma Durumlarının Değerlendirilmesine İlişkin Bir Model Önerisi
}

\author{
Celal Yiğit ${ }^{1}$, Melike Özyurt ${ }^{2}$, Hatice Adıyaman ${ }^{3}$ \\ ${ }^{1}$ Özel Sanko Okulları, Gaziantep, Türkiye \\ ${ }^{2}$ Temel Eğitim Bölümü, Ĕgitim Fakültesi, Gaziantep Üniversitesi, Gaziantep, Türkiye \\ ${ }^{3}$ Eğitim Bilimleri Enstitüsü, Gaziantep Üniversitesi, Gaziantep, Türkiye
}

Sorumlu Yazar: Celal Yiğit, celalyigit@gmail.com

Makale Türü: Araştırma Makalesi

Kaynak Gösterimi: Yiğit, C., Özyurt, M., \& Adıyaman, H. (2019). Okul öncesi öğrencilerinin programın kazanımlarına ulaşma durumlarının değerlendirilmesine ilişkin bir model önerisi. Eğitimde Kuram ve Uygulama, 15(3), 237-252. doi: $\underline{10.17244 / \mathrm{eku} .444573}$

\section{A Model Proposal to Assess Pre-School Students' Level of Achieving the Learning Standards}

\author{
Celal Yiğit ${ }^{1}$, Melike Özyurt ${ }^{2}$, Hatice Adıyaman ${ }^{3}$ \\ ${ }^{1}$ Özel Sanko Okullarl, Gaziantep, Turkey \\ ${ }^{2}$ Department of Primary Education, Faculty of Education, Gaziantep University, Gaziantep, Turkey \\ ${ }^{3}$ Graduate School of Educational Sciences, Gaziantep University, Gaziantep, Turkey
}

Corresponding Author: Celal Yiğit, celalyigit@gmail.com

Article Type: Research Article

To Cite This Article: Yiğit, C., Özyurt, M., \& Adıyaman, H. (2019). Okul öncesi öğrencilerinin programın kazanımlarına ulaşma durumlarının değerlendirilmesine ilişkin bir model önerisi. Eğitimde Kuram ve Uygulama, 15(3), 237-252. doi: $\underline{10.17244 / \mathrm{eku} .444573}$ 
2019, 15(3), 237-252

\title{
Okul Öncesi Öğrencilerinin Programın Kazanımlarına Ulaşma Durumlarının Değerlendirilmesine İlişkin Bir Model Önerisi
}

\author{
Celal Yiğit ${ }^{1}$, Melike Özyurt ${ }^{2}$, Hatice Adıyaman ${ }^{3}$ \\ ${ }^{1}$ Özel Sanko Okullarl, Gaziantep, Türkiye \\ ORCID: https://orcid.org/0000-0003-4896-9577 \\ ${ }^{2}$ Temel Ĕ̆itim Bölümü, Ĕgitim Fakültesi, Gaziantep Üniversitesi, Gaziantep, Türkiye \\ ORCID: https://orcid.org/0000-0003-4527-9343 \\ ${ }^{3}$ Eğitim Bilimleri Enstitüsü, Gaziantep Üniversitesi, Gaziantep, Türkiye \\ ORCID: $\underline{\text { https://orcid.org/0000-0002-5458-8538 }}$
}

\begin{tabular}{|c|c|}
\hline$\ddot{\mathbf{O ̈ z}}$ & Makale Bilgisi \\
\hline $\begin{array}{l}\text { Bu araştırmada okul öncesi eğitim programının değerlendirme basamağı için alternatif bir } \\
\text { değerlendirme modeli önerilmiş ve öğretmenlerin önerilen değerlendirme modeli ve } \\
\text { mevcut değerlendirme uygulamalarına ilişkin görüşlerinin tespit edilmesi amaçlanmıştır } \\
\text { Araştırma, karşılaştırmalı durum çalışması olarak desenlenmiştir. Araştırmanın çalışma } \\
\text { grubunu, 2015-2016 Eğitim-Öğretim Yılı'nda Gaziantep il merkezinde özel bir ilkokulun } \\
\text { anasınıfında görev yapan } 14 \text { öğretmen oluşturmaktadır. Araştırmanın verileri çalışma } \\
\text { grubu ile görüşmeler yapılarak toplanmıştır. Araştırmada veri toplama aracı olarak } \\
\text { araştırmacılar tarafından geliştirilen "Karşılaştırmalı Değerlendirme Formu" ve } \\
\text { "Değerlendirme Uygulamalarına İlişkin Öğretmen Görüşme Formu" kullanılmıştır. } \\
\text { Karşılaştırmalı Değerlendirme Formu bireysel görüşmelerle, Değerlendirme } \\
\text { Uygulamalarına İlişkin Öğretmen Görüşme Formu ise odak grup görüşmesi ile } \\
\text { öğretmenlere uygulanmıştır. Bireysel görüşmeler ile elde edilen verilerin analizinde } \\
\text { betimsel analiz tekniği, odak grup görüşmelerinden elde edilen verilerin analizinde ise } \\
\text { içerik analizi uygulanmıştır. Araştırma sonucunda Önerilen Değerlendirme Modeli ile } \\
\text { Mevcut Değerlendirme Uygulamalarında tespit edilen birçok eksiklik ve aksaklığın } \\
\text { giderilmiş olduğu tespit edilmiştir. Ayrıca Önerilen Değerlendirme Modelinin öğretmen } \\
\text { görüşlerine göre okul öncesi eğitim programının ölçme değerlendirme uygulamaları } \\
\text { kapsamında, ihtiyaca cevap veren, yeterli bir model olduğu ancak modelin öğrencilerin } \\
\text { ilgi ve yeteneklerini keşfetmede yeterli veri sağlama konusunda geliştirilmesi gerektiği } \\
\text { belirlenmiştir. }\end{array}$ & $\begin{array}{l}\text { Anahtar Kelimeler: Okul } \\
\text { öncesi eğitim programı, Okul } \\
\text { öncesi gelişim, Ölçme- } \\
\text { değerlendirme modeli }\end{array}$ \\
\hline
\end{tabular}




\section{A Model Proposal to Assess Pre-School Students' Level of Achieving the Learning Standards}

\begin{tabular}{|c|c|}
\hline Abstract & Article Info \\
\hline $\begin{array}{l}\text { In the study, an alternative assessment model is proposed for the assessment step of the } \\
\text { pre-school curriculum and the aim of the research is to establish teachers opinions } \\
\text { regarding the proposed and the current assessment model. A comparative case study } \\
\text { design was utilized in the research. The working group consisted of } 14 \text { teachers at a } \\
\text { kindergarten of a private school in the center of Gaziantep province in the 2015-2016 }\end{array}$ & $\begin{array}{l}\text { Keywords: Pre-school } \\
\text { curriculum, Pre-school } \\
\text { development, Assessment } \\
\text { model }\end{array}$ \\
\hline $\begin{array}{l}\text { Academic Year. The research data were collected through interviews with the research } \\
\text { group. A "Comparative Assessment Form" and "Teacher Interview Form Regarding }\end{array}$ & Article History: \\
\hline Assessment Applications" devised by the researchers were used as data collection tools. A & Received: 17 July 2018 \\
\hline descriptive analysis technique was used for analysis of the data gathered through & Revised: 30 May 2019 \\
\hline $\begin{array}{l}\text { individual interviews, whereas a content analysis technique was utilized for the analysis of } \\
\text { the data obtained through focus group interviews. As a result, it was seen that a number of }\end{array}$ & Accepted: 25 September 2019 \\
\hline shortcomings and problems in the Current Assessment Model could be ironed out thanks & Article Type: Research Article \\
\hline to the Proposed Assessment Model. Furthermore, it was specified that the Proposed & \\
\hline $\begin{array}{l}\text { Model is a satisfactory model that fulfills the needs within the scope of the assessment } \\
\text { practices of the pre-school curriculum, but should be improved so that it can provide } \\
\text { sufficient data for the exploration of students' needs and abilities. }\end{array}$ & \\
\hline
\end{tabular}




\section{Giriş}

Son yıllarda okul öncesi eğitimin yaygınlaşması konusunda Türkiye'de önemli çalışmalar yapılmaktadır. Milli Eğitim Bakanlığı (MEB) 2015-2019 stratejik planında okul öncesi eğitim imkânlarının yaygınlık ve yeterliliği zayıf yön olarak ele alınmış, okul öncesi eğitimde okullaşma, sistemin sorun ve gelişim alanlarından biri olarak belirlenmiş ve bunlara ilişkin stratejiler geliştirilmiştir (MEB, 2015). MEB 2015-2019 stratejik planı incelendiğinde okul öncesi eğitime katılımı arttıracak hizmet-sunum modellerinin çeşitlendirilmesinin ve okul öncesi eğitim imkânları kısıtlı hane ve bölgelerin bu eğitime erişimini destekleyecek şekilde yaygınlaştırılmasının öncelikli olarak hedeflendiği görülmektedir (MEB, 2015). Ancak uygulanan eğitim programının ne ölçüde etkili olduğunun değerlendirilmesi de bir diğer önemli konudur. Ölçme ve değerlendirme, eğitim-öğretim sürecinin her kademesinde öğrenmenin ve öğretimin önemli bir öğesidir. Okul öncesi eğitimde de; değerlendirme sayesinde, öğrencinin tüm gelişim alanlarındaki durumu hakkında detaylı ve periyodik olarak bilgi edinmek mümkündür (Demirel, 2012). Değerlendirme süreci eğitim sürecinin ve ürünlerinin amaçlanan doğrultuda gerçekleşip gerçekleşmediğine ilişkin bilgi sağlar (Ertürk,1998; Charlesworth, 1993; Roopnarine \& Johnson, 1993; Schweinhart, 2002; Şeker, 2012). Böylece, iyileştirme yapılacak alanlar belirlenerek elde edilen verilere göre eğitim-öğretimin iyileştirilmesi sağlanabilir.

Türkiye'de okul öncesi eğitimde MEB Talim Terbiye Kurulu onaylı Okul Öncesi Eğitim Programının uygulanmasının yanı sıra özellikle kreşlerde ve özel anaokullarında PYP, Montessori, High Scope ve Regio Emilio gibi okul öncesine ilişkin farklı eğitim modellerinin de uygulandığı görülmektedir. Tüm bu modellerde öğrenci kazanımlarının değerlendirmesinin süreç değerlendirme ile gerçekleştiği, değerlendirmenin programın önemli bir öğesidir (AMS, 2017; Cró, Pinho, \& Andreucci, 2012; Edwards, 2002; Epstein, Johnson, \& Lafferty; 2010; Georgeson \& Payler, 2013; Gestwicki, 2013; Gülkanat 2015; Montessori Australia, 2010; Roemer, 1999). Tüm bu okul öncesi eğitim modellerinde sistematik gözlemler yer alır. Bunu amacı, öğretmenin çocukların toplumsal, zihinsel, duygusal ve fiziksel gelişimlerini kolaylıkla takip edebilmesidir (Charlesworth, 1993; Izadpanah \& Günçe, 2014).

Türkiye'de okul öncesi eğitim programları 1952, 1989, 1994, 2002, 2006 ve 2013 y1llarında güncellenmiştir. Türkiye'de uygulanan okul öncesi eğitim programlarının genel özellikleri incelendiğinde programların esnek, öğrenci merkezli ve çocukların gelişim özelliklerine uygun bir şekilde hazırlandığı ve alınan geribildirimler neticesinde ihtiyaçları daha iyi karşılamak için güncellendiği söylenebilir (Düş̧ek \& Dönmez, 2012). Değerlendirme basamağının en detaylı olarak ele alındığı programın, 2006 programı olduğu görülmektedir (Sapsağlam, 2013). 2002'den bu yana uygulanan tüm MEB okul öncesi eğitim programlarında da değerlendirme basamağı çocukların değerlendirilmesi, programın değerlendirilmesi ve öğretmenin değerlendirilmesi olmak üzere üç boyuttan oluşmaktadır. Ancak Şıvgın (2005) ve Durmuşçelebi ve Akkaya'ya (2011) göre MEB okul öncesi eğitim programı öğretmenin kendisini, öğrencilerini ve programı nasıl değerlendireceği konusunda öğretmeni bilgilendirme ve ölçme ve değerlendirme örnekleri konusunda yetersiz kalmaktadır. Programda çocukların değerlendirilmesinin, öğretmenler tarafından doldurulan Gelişim Gözlem Formuyla kayıt altına alınması beklenmektedir. Öğretmenden diğer öğrencilerle karşılaştırma yapmadan her çocuğu kendi gelişimi çerçevesinde değerlendirmesi, günün farklı zamanlarında her çocuk için yaptığı gözlemi bir deftere not alması ve bu bilgileri sonradan her çocuk için doldurduğu gelişim gözlem formuna aktarması beklenmektedir. Çocuğun bütün gelişim alanlarını kapsayan, bilgi, beceri, tutum ve alışkanlıklarının genel bir şekilde özetlenmesi ise Gelişim Gözlem Formlarına bağlı kalınarak dönem sonlarında olmak üzere yılda iki defa oluşturulan Gelişim Raporları ile yapılmaktadır. Bu raporlarla aileye çocukları hakkında bilgi vermenin yanı sıra çocukların gelişimlerine ilişkin önerilerin sunulması da beklenmektedir. Ayrıca, çocuğun çalışmalarını içeren böylelikle gelişimi hakkında ipuçları veren portfolyo dosyalarının dönemde bir defa veliye sunulması, programın çocukların değerlendirme boyutunun bir diğer uygulamasıdır. Programda çocukların dâhil olduğu tek değerlendirme uygulaması ise yapılan etkinliklerin etkinlik sonrasında öğrencilerle değerlendirilmesidir. Burada öğretmenden beklenen betimleyici, duyuşsal, kazanımlara ilişkin ve yaşamla ilişkilendirmeye yönelik sorularla etkinliklerin uygulama sonrası öğrencilerle değerlendirilmesidir (MEB, 2013). Okul Öncesi Eğitim Programında yer alan Gelişim Gözlem Formu incelendiğinde ise formun bilişsel gelişim, motor gelişimi, dil gelişimi, sosyal ve duygusal gelişim ve öz bakım becerileri bölümünden oluştuğunu görülmektedir. Form ile ilgili olarak öğretmenin tarih belirterek bu gelişim alanlarına öğrenci ile ilgili gözlemlerini yazmalarını beklendiği ve bu formun doldurulma sıklığı ile ilgili bir 
açıklamanın olmadığı dikkat çekmektedir. Öğretim programlarında değerlendirme, öğrencinin kazanımlara ulaşma durumunu belirlemeye yönelik planlanmasına rağmen, okul öncesi eğitim programında öğrencinin değerlendirilmesi kazanımlarla ilişkilendirmemiş olup, gelişim alanlarının öğretmen gözlemleri ile doldurulması beklenmektedir. Formun doldurulma şekli ve sıklı̆̆ı da öğretmen inisiyatifine bırakılmıştır. 2006 programında, öğretmenlerin çocukların kazanımlara ulaşma durumunu işaretledikleri "Kazanım Değerlendirme Formu" değerlendirme basamağında yer almasına rağmen objektif bir şekilde doldurulmaması ve kullanılmaması nedeni ile 2013 okul öncesi eğitim programından kaldırılmıştır (Sapsağlam, 2013). Böylelikle, bu programda kazanımlara ulaşma durumu ile ilgili bir değerlendirme etkin bir şekilde yapılamamaktadır. Okul öncesi eğitim programında ayrıca öğrenci öz değerlendirmesi ile ilgili bir değerlendirmeye de yer verilmemiştir. Tüm bu durumlar öğrencilerin program kazanımlarına ne ölçüde ulaştığının belirlenmesinde, geride kalan öğrencilere bu kazanımlara ulaşmak için farklı etkinliklerin planlamasında ve ailelerin çocuğun program kazanımlarına erişimine bağlı olarak yeterlikleri hakkında bilgi verilmesinde geç kalınmasına neden olabilir. Sağlam'a (2008) göre çocukları tanıma ve değerlendirme tutarlı, sistemli ve objektif bir şekilde onlarla ilgili verileri toplama, kaydetme ve değerlendirme sonrası karar verme sürecidir. Ayrıca, çocuklar için uygun eğitim ortamlarının hazırlanabilmesi için, çocukları doğru bir şekilde tanımak ve değerlendirmek esastır (Topuz \& Kaya, 2016). Bu bağlamda, araştırmada okul öncesi eğitim programının değerlendirme basamağ için alternatif bir değerlendirme modeli önerilmiş ve öğretmenlerin önerilen değerlendirme modeli (ÖDM) ve mevcut değerlendirme uygulamalarına (MDU) ilişkin görüşlerinin tespit edilmesi amaçlanmıştır. $\mathrm{Bu}$ çerçevede araştırma soruları aşağıda sunulduğu şekli ile belirlenmiştir.

1. Öğretmenlerin mevcut değerlendirme uygulamalarına ilişkin görüşleri nelerdir?

2. Öğretmenlerin önerilen değerlendirme modeline ilişkin görüşleri nelerdir?

Alan yazında yer alan okul öncesi eğitim programlarına ilişkin araştırmalar incelendiğinde, Türkiye'de okul öncesi eğitim programlarının tarihsel gelişiminin araştırıldığı (Durmuş̧̧elebi \& Akkaya, 2011; Düşek \& Dönmez, 2012; Sapsağlam, 2013) ve MEB okul öncesi eğitim programlarının öğretmen görüşlerine göre incelendiği çalışmalara ulaşılmıştır (Aydın, 2010; Buldu, 2010; Cömert, 2003; Çivik, Ünüvar, \& Soylu, 2015; Durmuşçelebi \& Akkaya, 2011; Gülkanat, 2015; Gündoğdu, Turan, Kızıltaş, Çimen, \& Kayserili, 2008; Kandır-Özbey \& İnal, 2010; Köksal, Dağal, \& Duman, 2016; Topuz \& Kaya, 2016; Şıvgın, 2005). Ancak okul öncesi eğitim programının değerlendirme uygulamalarına ilişkin alternatif bir değerlendirme modeli önerisinin sunulduğu bir araştırmaya rastlanmamıştır. Bu yönü ile araştırmanın alan yazına katkı sağlaması beklenmektedir. Araştırmanın ayrıca, MDU'yu geliştirmeye yönelik bulgular sunması, alternatif bir değerlendirme modeli önermesi ve araştırma sonuçlarının MEB okul öncesi eğitim programını uygulayan anaokullarına yaygınlaştırılma potansiyeli olması yönüyle de önemli olduğu düşünülmektedir.

\section{Yöntem}

Nitel araştırma yönteminin kullanıldığı araştırmanın deseni karşılaştırmalı durum çalışmasıdır. Durum çalışmasında, sınırlı bir sistemin nasıl işlediği ve çalıştığı hakkında sistematik bilgi toplamak için çoklu veri toplama kullanılarak sistem derinlemesine incelenir (Chmiliar, 2010). Karşılaştırmalı durum çalışmasında, iki ya da daha çok durum çalışmasının yapılması ve bunların karşılaştırılması söz konusudur (Bogdan \& Biklen, 1998). Bu araştırmada okul öncesi eğitimi almakta olan çocukların, okul öncesi eğitim programının kazanımlarına erişme durumunu ölçmeye yönelik geliştirilen değerlendirme modeli ile mevcut ölçme değerlendirme uygulamaları öğretmen görüşlerine göre incelendiği için araştırmanın deseni karşılaştırmalı durum çalışması olarak belirlenmiştir.

\section{Önerilen Değerlendirme Modeli (ÖDM)}

ÖDM'de aylık olarak öğrencilerin o ayın kazanımlarına ulaşma durumları öğretmenler tarafından değerlendirilir. Aylık değerlendirmelerin yanı sıra birinci dönemin ve ikinci dönemin sonunda genel değerlendirmeler yapılır. Her ay öğretmenler zümre toplantılarında sonraki ayda ele alınacak ve değerlendirilecek kazanımları Bilişsel Gelişim, Dil Gelişimi, Sosyal ve Duygusal Gelişim, Motor Gelişim ve Öz Bakım Becerileri alanlarına göre belirler. Öğretmenler her öğrencinin kazanımlara ulaşma durumunu bireysel gözlem, soru-cevap, gösterip yaptırma, anekdot kaydı tekniklerini kullanarak bir ay boyunca gözlemler. Ay sonunda öğrencileri aşağıdaki puanlama sistemine göre değerlendirir.

1: Temel Düzey Alt1

2: Temel Düzey 


\section{3: Yeterli}

4: İleri Düzey

Öğretmenler değerlendirmelerini çevrim içi bir programa girer. Programdan, öğrenci kazanım puanları, şube kazanım puanları, öğrenci performans seviyeleri, şube performans seviyeleri, öğrenci madde analizi, şube madde analizi, şube gelişimsel bilgi haritaları ve öğrenci gelişimsel bilgi haritaları vd. raporlar alınır. Her ay sonunda, ilgili şube (yaş grubuna göre) öğretmenlerinin, rehber öğretmenin, okul yöneticisinin ve ölçme-değerlendirme biriminin katılımı ile değerlendirme toplantısı yapılarak şubeler bazında öğrencilerin güçlü ve geliştirilmesi gereken yönleri tespit edilir. Toplantılarda yapılan değerlendirme sonucunda öğrencilerin ilgili aydaki gelişimsel performansına göre alınmas1 gereken tedbirler belirlenir.

$\mathrm{Bu}$ sonuçlara göre öğrenci ve sınıf bazında tamamlama ve iyileştirme çalışmaları planlanarak uygulanır, dönem sonu değerlendirmelerinde öğrencilerin kazanımlara ulaşma durumları yeniden değerlendirilir.

\section{Çalışma Grubu}

Araştırmanın çalışma grubunu, 2015-2016 Eğitim-Öğretim Yılı'nda Gaziantep il merkezinde özel bir ilkokulun anasınıfında görev yapan 14 öğretmen oluşturmaktadır. Çalışma grubunun tamamı kadın öğretmenlerden oluşmaktadır ve çalışma grubunda yer alan öğretmenlerin dokuzu altı yıl ve üzeri mesleki deneyime sahiptir. Çalışma grubunda görevde ilk y1lı olan öğretmen bulunmamaktadır.

Araştırmanın yapıldığı dönemde ilgili anaokulunda toplam 153 çocuk bulunmaktadır. Dört yaş grubunda (4860 ay) $24 \mathrm{kız} \mathrm{( \%} \mathrm{47,05)} \mathrm{ve} 27$ erkek (\% 52,94) olmak üzere toplam 51 çocuk ve beş yaş grubunda (60- 72 ay) $47 \mathrm{k} 1 \mathrm{z}$ $(\%$ 46,07) ve 55 erkek $(\%$ 53,92) olmak üzere toplam 102 çocuk eğitim görmektedir.

\section{Veri Toplama Araçları}

Araştırmanın verileri araştırmacılar tarafından geliştirilen "Karşılaştırmalı Değerlendirme Formu" ve "Değerlendirme Uygulamalarına İlişkin Öğretmen Görüşme Formu" olmak üzere iki farklı görüşme formu kullanılarak toplanmıştır. "Karşılaştırmalı Değerlendirme Formu” sekiz adet yapılandırılmış sorudan oluşmaktadır. Bu formda yer alan sorular kesinlikle katılıyorum, katılıyorum, kararsızım, katılmıyorum ve kesinlikle katılmıyorum şeklinde beşli likert tipinde derecelendirilmiştir. Formda yer alan sorularla öğretmenlerin, ÖDM ile MDU'yu; öğrencilerin gelişimlerini ölçme, ilkokula hazır bulunuşluğunu ölçme, gruba göre durumlarını ölçme, öğrencilerin ilgi ve yeteneklerini ölçme, süreç değerlendirme yapma ve aileye bilgi vermek için yeterli veri sağlama boyutlarında karşılaştırması istenmiştir. Araştırmanın diğer bir veri toplama aracı olan "Değerlendirme Uygulamalarına İlişkin Öğretmen Görüşme Formu” ise yarı yapılandırılmış nitelikte olup, altı açık uçlu sorudan oluşmaktadır. Bu görüşme sorular1;

1- Mevcut değerlendirme uygulamalarının güçlü yönleri nelerdir? Açılar mısınız?

2- Mevcut değerlendirme uygulamalarının zayıf yönleri nelerdir? Açıklar mısınız?

3- Mevcut değerlendirme uygulamaları öğrencilerin kazanımlara ulaşma durumlarının değerlendirilmesi için yeterli midir? Neden?

4- Önerilen değerlendirme modelinin güçlü yönleri nelerdir? Açıklar mısınız?

5- Önerilen değerlendirme modelinin zayıf yönleri nelerdir? Açıklar mısınız?

6- Önerilen değerlendirme modeli öğrencilerin kazanımlara ulaşma durumlarının değerlendirilmesi için yeterli midir? Neden?

Ölçme araçları geliştirilirken geçerlik güvenirlik çalışmaları kapsamında görüşme formları Gaziantep Üniversitesinde görevli, ölçme değerlendirme, okul öncesi eğitimi, Türkçe eğitimi ana bilim dallarından toplam beş uzmanın ve iki okul öncesi öğretmeninin görüşüne sunulmuştur. Ayrıca iki okul öncesi öğretmeni ile pilot uygulama yapılmıştır. Uzman görüşleri ve pilot uygulama sonrasında ölçeklere son şekli verilmiştir.

\section{Verilerin Toplanması}

Görüşme, nitel araştırmada birincil veri kaynaklarından biridir (Merriam \& Tisdell, 2015:137). Merriam (2009), durum çalışmaları için en iyi veri toplama tekniklerinin çalışmanın katılımcısıyla birlikte yürütülen nitel görüşmeler 
aracılığı ile olduğunu açıklamıştır (Aktaran, Abdullah, Zuhairi, Zailaini, \& Jamaluddin, 2015). Odak grup görüşmeleri ile katılımcıların farklı yönlerine dair derinlemesine, çok boyutlu ve detaylı bilgi edinmesi amaçlanır. (Bowling, 2002, akt. Çokluk, Y1lmaz, \& Oğuz, 2011; Gibbs, 1997; Kitzinger, 1994; 1995; Krueger, 1994; Stewart \& Shamdasani, 1990). Araştırma verileri bireysel görüşme ve odak grup görüşmesi teknikleri kullanılarak araştırmacılar tarafından üç aşamada toplanmıştır. Bu süreçte iki defa odak grup görüşmesi ve bir defa da bireysel görüşmeler gerçekleştirilmiştir. Sürece öğretmenlerle birinci odak grup görüşmesi yapılarak başlanmıştır. $\mathrm{Bu}$ görüşmede öğretmenlere “Değerlendirme Uygulamalarına İlişkin Öğretmen Görüşme Formu”nun ilk üç sorusu yöneltilerek öğretmenlerin MDU’ya ilişkin görüşleri saptanmıştır. Sonrasında öğretmenlere ÖDM tanıtılmış, uygulama örnekleri sunulmuştur. Model okul idaresinin iş birliği ile öğretmenler tarafından bir eğitim- öğretim dönemi boyunca uygulanmış, öğrenci değerlendirmeleri önerilen modele göre yapılmıştır. Ayrıca ihtiyaç durumunda öğretmenlerin uygulamaya ilişkin soruları yanıtlanmış, Modelin doğru bir şekilde uygulanmasına destek sağlanmıştır. Dönem sonunda uygulamalar tamamlandıktan sonra öğretmenlerle ikinci bir odak grup görüşmesi yapılmış ve "Değerlendirme Uygulamalarına İlişkin Öğretmen Görüşme Formu”nda yer alan ÖDM’ye ilişkin üç soru öğretmenlere yöneltilmiştir. Odak grup görüşmelerinden sonra öğretmenlerle bireysel görüşmeler yapılarak her bir öğretmene "Karşılaştırmalı Değerlendirme Formu" uygulanmıştır. Her bir odak görüşmesi yaklaşık 40 dakika sürmüş olup ses kayıt cihazı ile kayıt altına alınmıştır. Bireysel görüşmelerin her biri ise yaklaşık 10 dakikada gerçekleştirilmiştir. Bu görüşmelerde ses kayıt cihazı kullanılmamış olup öğretmenlerin verdikleri yanıtlar doğrultusunda yapılandırılmış görüşme formunun likert tipi derecelendirme kısmı doldurularak görüşme kayıt altına alınmıştır.

\section{Verilerin Analizi}

"Karşılaştırmalı Değerlendirme Formu" kullanılarak yapılan bireysel görüşmelerden elde edilen veriler betimsel analize tabi tutularak, öğretmenlerin MDU ve ÖDM'ye ilişkin görüşlerinin frekans dağılımları belirlenmiştir. Betimsel analiz daha önceden belirlenen temalar çerçevesinde elde edilen verilerin özetlenip yorumlanmasıdır (Yıldırım \& Şimşek, 2006, s. 224).

"Değerlendirme Uygulamalarına İlişkin Öğretmen Görüşme Formu" kullanılarak yapılan odak grup görüşmelerinden elde edilen veriler ise öncelikle ses kayıt cihazından bilgisayar ortamında Word dosyasına aktarılmıştır. Ayrıca katılımcıların isimleri saklı tutularak kodlama yoluna gidilmiş olup katılımcılar K1, K2, vd. şeklinde kodlanmıştır. Bu veriler içerik analizine tabi tutularak çözümlenmiştir. İçerik analizi, kodlamalara dayalı, bir metnin bazı sözcüklerinin daha küçük içerik kategorileri ile özetlendiği sistematik, tekrarlanabilir bir teknik olarak tanımlanmaktadır (Büyüköztürk vd., 2008, s. 244).

Yapılan analizin geçerlik, güvenirlik çalışması kapsamında veriler araştırmacılar tarafından ayrı ayrı kodlanmış ve sonrasında kod uyumuna bakılmıştır. Farklılık gösteren durumlar için araştırmacılar tarafından birlikte değerlendirme yapılarak durumu en uygun ifade eden kodun belirlenmesi yoluna gidilmiş, kodlayıcılar arasında yüzde yüz uyum yakalanmıştır. Ayrıca, bulgular sunulurken doğrudan alıntılara yer verilmiştir.

\section{Bulgular}

$\mathrm{Bu}$ kısımda öğretmenlerin MDU ve ÖDM'ye ilişkin görüşleri; bireysel ve odak grup görüşmelerden elde edilen verilerin analizi sonucu ulaşılan bulgular çerçevesinde sunulmaktadır. Bu bağlamda Karşılaştırmalı Değerlendirme Formundan elde edilen verilerin betimsel analizi sonucu ulaşılan MDU ve ÖDM'ye ilişkin öğretmen görüşleri Tablo 1 'de sunulmaktadir.

Tablo 1'de görüleceği üzere MDU'ya yönelik yapılan değerlendirmede, öğretmenler tarafindan görüşme formunda yer alan tüm maddeler için en sık belirtilen görüşün "katılmıyorum" olduğu görülmektedir. Bununla birlikte MDU'ya ilişkin görüşme formunda yer alan hiçbir madde için öğretmenler "kesinlikle katıllyorum" görüşünü belirtmemişlerdir. Öğretmenlerin çok azı bu uygulamaların, öğrencilerin gelişim alanlarına göre düzeylerini saptama imkânı sağlaması (3), geliştirilmesi gereken yönlerini saptaması (1), grubun gerisinde veya ilerisinde olan öğrencileri belirlemede yeterli veri sağlaması (3) ve öğrencilerin gelişim durumlarına ilişkin "süreç değerlendirmesi” yapması imkânı sağlaması (2) yönüyle MDU'ya ilişkin görüşlerini "katıllyorum" olarak ifade etmişlerdir. Bu bulgular ışığında öğretmen görüşlerine göre MDU'nun, öğrencilerin gelişim alanlarına göre düzeylerini ve geliştirilmesi gereken yönlerini saptama, öğrencilerin ilkokula hazır bulunuşluğunu belirleme, grubun gerisinde veya ilerisinde olan öğrencileri belirleme, bu öğrenciler için öğretimi farklılaştırma, öğrencilerin ilgi ve yeteneklerini keşfetme, ailelere çocuklarının gelişimleri hakkında nitelikli bilgi verme konularında yeterli veri sağlama ve öğrencilerin gelişim durumlarına ilişkin "süreç değerlendirmesi” yapma imkânı sağlamada yetersiz veya eksik olduğu söylenebilir. 
Tablo 1. MDU ve ÖDM' ye ilişkin öğretmen görüşleri

\begin{tabular}{|c|c|c|c|c|c|c|c|c|c|c|}
\hline & \multicolumn{5}{|c|}{$\begin{array}{l}\text { Mevcut Değerlendirme } \\
\text { Uygulamaları }\end{array}$} & \multicolumn{5}{|c|}{$\begin{array}{c}\text { Önerilen Değerlendirme } \\
\text { Modeli }\end{array}$} \\
\hline & 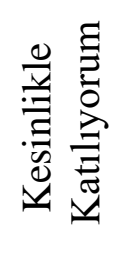 & 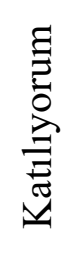 & 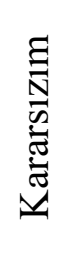 & 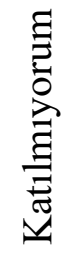 & 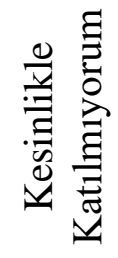 & 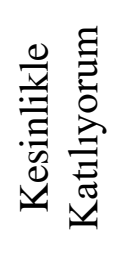 & 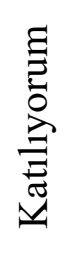 & 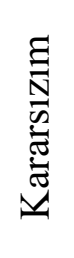 & 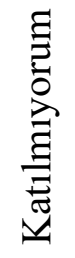 & 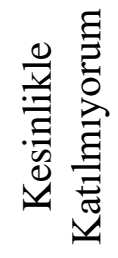 \\
\hline & $\mathrm{f}$ & $\mathrm{f}$ & $\mathrm{f}$ & $\mathrm{f}$ & $\mathrm{f}$ & $\mathrm{f}$ & $\mathrm{f}$ & $\mathrm{f}$ & $\mathrm{f}$ & $\mathrm{f}$ \\
\hline $\begin{array}{l}\text { 1. Öğrencilerin gelişim alanlarına } \\
\text { göre düzeylerini saptama imkânı } \\
\text { sağlıyor. }\end{array}$ & & 3 & 1 & 10 & & 8 & 6 & & & \\
\hline $\begin{array}{l}\text { 2. Öğrencilerin gelişim alanlarına } \\
\text { göre geliştirilmesi gereken } \\
\text { yönlerini saptama imkânı } \\
\text { sağlıyor. }\end{array}$ & & 1 & 5 & 8 & & 13 & 1 & & & \\
\hline $\begin{array}{l}\text { 3. Öğrencilerin ilkokula hazır } \\
\text { bulunuşluğu hakkında yeterli veri } \\
\text { sağlıyor. }\end{array}$ & & & 2 & 8 & 4 & 6 & 8 & & & \\
\hline $\begin{array}{l}\text { 4. Grubun gerisinde veya } \\
\text { ilerisinde olan öğrencileri } \\
\text { belirlemede yeterli veri sağliyor. } \\
\text { 5. Grubun gerisinde veya }\end{array}$ & & 3 & 1 & 8 & 3 & 11 & 3 & & & \\
\hline $\begin{array}{l}\text { ilerisinde olan öğrenciler için } \\
\text { öğretimi farklılaştırma imkânı } \\
\text { sağlıyor. }\end{array}$ & & & 1 & 11 & 2 & 11 & 3 & & & \\
\hline $\begin{array}{l}\text { 6. Öğrencilerin ilgi ve } \\
\text { yeteneklerini keşfetmede yeterli } \\
\text { veri sağliyor. }\end{array}$ & & & 1 & 12 & 1 & 4 & 5 & 5 & & \\
\hline $\begin{array}{l}\text { 7. Öğrencilerin gelişim } \\
\text { durumlarına ilişkin "süreç } \\
\text { değerlendirmesi” yapma imkânı } \\
\text { sağlıyor. }\end{array}$ & & 2 & & 10 & 2 & 10 & 4 & & & \\
\hline $\begin{array}{l}\text { 8. Ailelere çocuklarının } \\
\text { gelişimleri hakkında nitelikli bilgi } \\
\text { vermek için yeterli düzeyde veri } \\
\text { sağlıyor. }\end{array}$ & & & 3 & 8 & 3 & 7 & 7 & & & \\
\hline
\end{tabular}

ÖDM için ise görüşme formunda yer alan tüm maddeler, öğretmenler tarafından "kesinlikle katılıyorum” veya "katıllyorum" görüşleri ile değerlendirilmiştir. Model sadece "öğrencilerin ilgi ve yeteneklerini keşfetmede yeterli veri sağlıyor" maddesi kapsamında beş öğretmen tarafından "kararsızım" görüşü ile değerlendirilmiştir. Bu bulgular çerçevesinde, ÖDM'nin öğretmen görüşlerine göre görüşeme formunda yer alan değerlendirme kriterleri bağlamında ihtiyaca cevap veren, yeterli bir model olduğu ancak modelin öğrencilerin ilgi ve yeteneklerini keşfetmede yeterli veri sağlama konusunda geliştirilmesi gerektiği söylenebilir.

Değerlendirme Uygulamalarına İlişkin Öğretmen Görüşme Formu kullanılarak gerçekleştirilen odak grup görüşmelerinden elde edilen verilerin içerik analizi sonucu ulaşılan MDU ve ÖDM'nin güçlü ve zayıf yönleri ile kazanımlara ulaşma durumunu ölçmedeki yeterliliğine ilişkin öğretmen görüşleri ise Tablo 2'de sunulmaktadır.

Tablo 2'de yer aldığı üzere, MDU'ya ilişkin öğretmenlerle yapılan odak grup görüşmelerinden elde edilen bulgular, uygulamanın güçlü yönleri, zayıf yönleri ve kazanımlara ulaşma durumunu ölçmede yeterliliği olmak üzere üç tema altında toplanmıştır. Öğretmen görüşlerine göre MDU'nun en güçlü yönü uygulamaların detaylı bilgi sağlamasıdır. Bununla birlikte uygulamaların objektif veri sağlaması, bireysel farklılıkları ortaya çıkarması, örnek 
formların olması da MDU'nun güçlü yönleri olarak öğretmenler tarafından ifade edilmiştir. Odak grup görüşmesinde öğretmenlere MDU'nun güçlü yönleri sorulmasına rağmen iki öğretmen uygulamaların sınırlılığına dikkat çekmiştir. Bu bulgulara ilişkin öğretmenlerin ifadelerinden bazıları aşağıda sunulmaktadır.

Bireysel farklılıkları ortaya çıkarıp, öğrenci gelişimi ile ilgili detaylı bilgi sağlamaktadır (K1). Değerlendirmede yer alan kriterleri her çocuk için birebir uygulayarak değerlendirmek çocuk hakkında daha iyi bilgi ve becerisini görmemize yardımcı olmuştu (K7). Gözleme dayalı değerlendirmede ögrenciler değerlendirildiklerini hissetmeden kendilerini doğal bir şekilde ifade ediyor. Öğrencilerin kendi doğal ortamlarında olmasından dolayl veriler objektif olarak belirlenir (K2). Örnek formların olması (anekdot formu gibi) (K4). Güçlü yönü yoktur (K12).

Öğretmen görüşlerine göre MDU'nun en zayıf yönünün detaylı değerlendirmenin yapılaması olduğu tespit edilmiştir. Öğretmenler bu uygulamaların genel bir gözlem kaydı ile sınırlı olması, tüm gelişim alanlarında yeterli veri sağlayamaması, ayrıntılı kazanım değerlendirme yapılamaması, çoğunlukla akademik gelişime odaklanılması, ölçümün değerlendirilmemesi, amacın net olmaması, zaman alıcı olması gibi zayıf yönlerinin de bulunduğunu ifade etmişlerdir. Bu bulgulara ilişkin öğretmenlerin ifadelerinden bazıları aşağıdaki gibidir.

Detaylı bir değerlendirme sistemi olmadığını düşünüyorum. Elde ettiğim veriler çok sınırlı. Öğrencilerin neyi bildiğini anladı̆̆ını öğrenmemde yeterli değil. Öğrencilerin anlamakta güçlük çektiği alanlarl, zayıf yönlerini ve bilgi boşluklarını tespit etmeye yönelik detaylı bir uygulama olmadı̆̆ını düşünüyorum (K2). Detaylı bir değerlendirme olmaması (K11). İileştirme için yeterli veri sağlamıyor. Sadece gözlem kaydı tutmayı sağllyor. Grubun genelini ve bireysel olarak ögrenciyi değerlendirmek ve geliştirmek için yeterli veri sağlamıyor. Zaylf kallyor(K14). Ayrıntılı kazanım değerlendirme yapılmadiğı için yalnızca öğretmenin düşüncedeki değerlendirmesiyle sinırlı kallyor (K8). Doldurulan değerlendirme formları sonuca ulaştırmıyordu (K5). Kayıtlar tutuluyordu fakat hedef belli değildi, değerlendirmesi yapılmıyordu yani sonuç yok (K13). Tik atma yöntemi ile yapılan değerlendirmede çok fazla madde olması. Zamanın fazlaca kaybına neden olmaktaydı ve bir çocuğa harcanan süre sınıfın günlük akışını bozucu nitelikteydi $(K 7)$.

MDU'nun kazanımlara ulaşma durumunu ölçmede yeterliliğine ilişkin ise sekiz öğretmen yeterli değil şeklinde görüş bildirirken, sadece bir öğretmen yeterli olduğunu ifade etmiştir. Bu bulgulara ilişkin öğretmenlerin bazı ifadeleri aşağıda yer almaktadır.

Yeterli olduğunu düşünmüyorum. Süreç sırasında değil, süreç bitiminde değerlendirilen ve eksik yönlerin telafisini ele alma şeklinde değil sadece çocuk ne biliyor ve bilmiyorsa gösteren bir uygulama oluyordu (K7). Hayır (K10).Yeterli değil. Yanıldığımız noktalar olabilir. Her çocuğun her kazanıma ne oranda ulaşmış olduğunu ölçemiyorum. Gözlem yoluyla anlamaya çalışıyorum. Ama gözlem formları sonrasında bir işe yaramıyor (K14). Değerlendirmeler bazı durumlarda sübjektif olabiliyor. Aynı ögrenciyi ilgilendiren iki ögretmenin sonuçları farklı çıkabiliyor. Daha gerçekçi detaylı bir değerlendirme yöntemi olmadiğı için öğrencilerin bulunduğu durumu ve ulaşması beklenen standartları değerlendirme imkanı sunmuyor (K2). Yeterlidir (K1).

Tablo 2. MDU ve ÖDM'nin güçlü ve zayıf yönleri ile yeterliliğine ilişkin öğretmen görüşleri

\begin{tabular}{|c|c|c|c|c|}
\hline \multirow[b]{2}{*}{ TEMA } & \multicolumn{2}{|l|}{ Mevcut Değerlendirme Modeli } & \multicolumn{2}{|l|}{ Önerilen Değerlendirme Modeli } \\
\hline & Kod & $\mathrm{f}$ & Kod & $\mathrm{f}$ \\
\hline \multirow{15}{*}{ Güçlü Yönler } & detaylı bilgi sağlama & 3 & $\begin{array}{l}\text { bireysel ve gruplar arası değerlendirmeyi } \\
\text { sağlama }\end{array}$ & 5 \\
\hline & bireysel farkl11ıkları ortaya çıkarma & 1 & çocukları daha iyi tanımayı sağlama & 4 \\
\hline & gelişimsel alanlara göre değerlendirme & 1 & $\begin{array}{l}\text { öğretmene öz değerlendirme yapma firsatı } \\
\text { sağlama }\end{array}$ & 4 \\
\hline & kayıt altına alma & 1 & objektif değerlendirme & 3 \\
\hline & $\begin{array}{l}\text { grup içinde öğrencinin durumunu } \\
\text { belirleme }\end{array}$ & 1 & detaylı değerlendirme & 3 \\
\hline & bireysel gelişimi gözlemleme & 1 & süreç değerlendirme & 3 \\
\hline & gözleme dayalı değerlendirme & 1 & $\begin{array}{l}\text { geliştirilmesi gereken yönler } \\
\text { hakkında bilgi sağlama }\end{array}$ & 3 \\
\hline & doğal ortamında değerlendirme & 1 & ölçüm sonrası değerlendirme yapılması & 3 \\
\hline & örnek formların olması & 1 & $\begin{array}{l}\text { tüm gelişim alanlarında yeterli veri } \\
\text { sağlayama }\end{array}$ & 2 \\
\hline & & & her bir öğrenciyi değerlendirebilme & 2 \\
\hline & & & öğrenci gelişimini takip etme & 2 \\
\hline & & & bireysel farklılıkları ortaya çıkarma & 2 \\
\hline & & & çeşitli ve doyurucu bilgi sağlama & 1 \\
\hline & & & $\begin{array}{l}\text { ilkokula hazır bulunuşluk hakkında } \\
\text { veri sağlama }\end{array}$ & 1 \\
\hline & & & değerlendirmenin kayıt altına alınması & 1 \\
\hline
\end{tabular}




\begin{tabular}{ll} 
& tüm gelişim alanlarında yeterli veri \\
& sağlamaması \\
& genel bir gözlem kaydı ile sınırlı olması \\
& ayrıntılı kazanım değerlendirme \\
& yapılmaması \\
& ölçümün değerlendirilmemesi \\
& amacın net olmaması \\
& bireysel farklılıklar konusunda yeterli \\
Zayıf Yönler & bilgi vermeme \\
& objektif veri sağlayamama \\
& çoğunlukla akademik gelişime \\
& odaklanma \\
& form doldurmanın zaman alıcı olması \\
Kazanımlara & yeterli değil \\
ulaşma durumunu & \\
ölçmede & yeterli \\
yeterlilik & \\
\hline
\end{tabular}

tüm gelişim alanlarında yeterli veri sağlamaması genel bir gözlem kaydı ile sınırlı olması ayrıntılı kazanım değerlendirme yapılmaması amacin net olmaması bilgi vermeme objektif veri sağlayamama çoğunlukla akademik gelişime odaklanma doldurmanın zaman alıcı olması

ÖDM'ye ilişkin öğretmenlerle yapılan odak grup görüşmelerinden elde edilen bulgular da MDU'nun bulgularına benzer şekilde, uygulamanın güçlü yönleri, zayıf yönleri ve kazanımlara ulaşma durumunu ölçmede yeterliliği olmak üzere üç tema altında belirlenmiştir. Öğretmen görüşlerine göre ÖDM’nin en güçlü yönlerinin bireysel ve gruplar arası değerlendirmeyi sağlama, çocukları daha iyi tanımayı sağlama, öğretmene öz değerlendirme yapma firsatı sağlama, objektif, detaylı ve süreç değerlendirme yapma, geliştirilmesi gereken yönler hakkında bilgi sağlama ve ölçüm sonrası değerlendirme yapılması olarak belirlenmiştir. Bu bulgulara ilişkin öğretmenlerin ifadelerinden bazıları şu şekildedir.

Çocukları daha iyi tanımamı sağlıyor. Aralarındaki bireysel farklılıkları ayırt ederken daha objektif oluyorum. Eksik gördügüm gelişmeleri ne şekilde tamamlamam gerektĭgi konusunda bana yardımcı oluyor (K3). “... bireysel olarak her ögrenci için farklı etkinliklerle yeniden çalışılması gereken kazanımları belirleyip ek çalışma imkanı veriyor. Öğrenci hakkında çeşitli ve doyurucu bilgi sağllyor, aile görüşmeleri için veri sağlıyor. Öğretmene kendini değerlendirme firsatı sağllyor (K14). Bireysel farklılıklar hakkında ve Grubun/bireyin geliştirilmesi gereken yönler hakkında bilgi veriyor. Hiçbir öğrenci gözden kaçmıyor. Öğretmenin kendi çalışmalarını değerlendirmesine olanak sağlıyor. Süreç değerlendirmesi yapılıyor. Illkokula hazır bulunuşluk hakkında veri sağllyor (K4).

ÖDM'nin öğretmen görüşlerine göre zayıf yönü ise modelin çocuğun ilgi ve yeteneklerini belirleyebilme konusunda yetersiz kalmasıdır. Bir iki öğretmen görüşü ile sınırlı olmakla birlikte öğretmenler ÖDM'nin iş yükü getirmesini, çocuğun duygu durumunun değerlendirmeyi etkileyebilme durumunu ve değerlendirme sonrasında yapılacaklara ilişkin planlama sorunlarını da modelin zayıf yönleri olarak ifade etmişlerdir. Bu konudaki öğretmenlerin bazı ifadeleri aşağıda sunulmaktadır.

Değerlendirme ögrencinin ilgi ve yeteneklerini ortaya koyma yönünden yetersiz (K6). Çocuğun özel yeteneğini ortaya koymuyor (K7). Öğrencilerimin yeteneklerini belirleme konusunda zayıf kaldığını düşünüyorum (K9). Yeteneklerle ilgili veri sağlamıyor (K11). Yapılan uygulama anasınıfinda olduğu için bazen farklılıklar gösterebiliyor. Bu yaştaki çocuklar duygusal olarak değişim içinde olduklarında bazen farklı sonuçlarla karşılaşabiliyoruz. Ĕger değerlendirilen çocuk hastaysa, sıkılmışsa veya mutsuzsa değerlendirme sonuçlarını etkiliyor (K2).

ÖDM'nin çocukların kazanımlara ulaşma durumunu ölçmede yeterliliğine ilişkin ise sekiz öğretmen yeterli, altı öğretmen ise kısmen yeterli şeklinde görüş bildirmiştir. Modeli araştırmaya katılan hiçbir öğretmen yetersiz olarak değerlendirmemiştir. Bu bulgulara ilişkin öğretmenlerin bazı ifadeleri şu şekildedir.

Kişisel gelişimime ve öğrencilerin kazanımlara ulaşma düzeyi konusunda büyük fayda sağladı (K4). Kesinlikle yeterli. Ulaşılmayan kazanım tekrar değerlendiriliyor. Çocuğun o kazanıma ulaşması için gerekli destek să̆lanıyor. Etkinlikler çeşitlendiriliyor (K13). Bu modelin önceki uygularımızla klyasladığımda ciddi anlamda çok daha yeterli olduğunu düşünüyorum (K14). 


\section{Sonuç ve Tartışma}

Araştırma sonucunda öğretmen görüşlerine göre MDU'nun; öğrencilerin gelişim alanlarına göre düzeylerini ve geliştirilmesi gereken yönlerini saptama, ilkokula hazır bulunuşluğunu belirleme, grubun gerisinde veya ilerisinde olan öğrencileri belirleme, bu öğrenciler için öğretimi farklılaştırma, öğrencilerin ilgi ve yeteneklerini keşfetme, ailelere çocuklarının gelişimleri hakkında nitelikli bilgi verme konularında yeterli veri sağlayamadığı ve öğrencilerin gelişim durumlarına ilişkin "süreç değerlendirmesi” yapmak için eksik kaldığı tespit edilmiştir. Okul öncesi dönemde değerlendirme çok önemlidir (Özsırkıntı, Akay, \& Bolat, 2014). Çünkü bu dönemde çocuklar hızlı gelişim gösterir ve bu dönemdeki gelişim özelliklerini ileriki dönemlere taşırlar. Bu nedenle her alandaki gelişim durumlarının doğru bir şekilde ortaya konulması gerekir (Kan, 2007). Ayrıca öğretmenler için öğrencileri tanıma ve değerlendirme üreci bir gerekliliktir (Topuz \& Kaya, 2016). Bu bağlamda araştırma kapsamında, mevcut uygulamalara ilişkin belirlenen eksikliklerin giderilmesinin bir gereklilik olduğu söylenebilir.

Araştırmada MDU'nun güçlü yönlerine ilişkin sınırlı sayıda öğretmen görüş bildirilmiş olup, detaylı bilgi sağlamanın, az sayıdaki öğretmen görüşüne göre mevcut uygulamaların en güçlü yönü olduğu tespit edilmiştir. Ancak araştırmada MDU'nun güçlü yönleri konusunda öğretmenler arasında görüş birliği olmadığı da belirlenmiştir. Çünkü değerlendirme için yeterli veri sağlayamama, mevcut değerlendirme uygulamalarının öğretmenler tarafından en sık ifade edilen zayıf yönüdür. Bununla birlikte okul öncesi eğitim programında, değerlendirmenin çok yönlü olması, programın temel özellikleri arasında yer almaktadır (MEB, 2013). Ancak araştırma sonucuna göre MDU genel bir gözlem kaydı ile sınırlı olup, tüm gelişim alanlarında yeterli veri sağlayamamaktadır. Ayrıca uygulamaların zaman alıcı olması, uygulamalar kapsamında ayrıntılı kazanım değerlendirmesi yapılamaması, çoğunlukla akademik gelişime odaklanılması, ölçümün değerlendirilmemesi, uygulamalarda amacın net olmaması öğretmenlerin görüşlerine göre MDU'nun diğer zayıf yönleridir. Özsırkıntı, Akay ve Bolat'a (2014) göre de 2013 Okul Öncesi Eğitim Programının değerlendirme uygulamaları çerçevesinde eğitim öğretim sürecinde ayrıntılı ve profesyonel değerlendirme yapılamamaktadır. Benzer şekilde, Durmuşçelebi ve Akkaya’ya (2011) göre 2006 Okul Öncesi Eğitim Programının "Değerlendirme" boyutu öğretmen görüşlerine göre yetersiz görülmektedir. Arslan ve İlkay (2015) ise 2013 Okul öncesi eğitim programının çok yönlü bir değerlendirme gerektirdiği belirtmiştir. Ancak, öğretmenlerin okul öncesinde değerlendirme formu doldurmaya ihtiyaç olmadığını düşündüklerini, bu uygulamanın masraflı olduğu ve aylara göre kazanım değerlendirme formunun doldurmanın güç olduğu görüşünde olduklarını belirlemiştir. Bununla birlikte Nah ve Kwak (2011) de öğretmenlerin sistematik kullanılan formların çocuklar için sınırlı bilgi verdiği görüşüne sahip olduklarını tespit etmiştir. Topuz ve Kaya (2016) ise öğretmenlerin değerlendirme kapsamında doldurulması beklenen formların işlevsiz olduğunu düşündüklerini belirlemiştir. Öğretmenlerin formları işlevsiz bulmaları araştırma kapsamında MDU'nun zayıf yönü olarak tespit edilen uygulamalarda amacın net olmaması bulgusunu açılar niteliktedir. Araştırmada ayrıca MDU öğrencilerin kazanımlara ulaşma durumunu ölçme konusunda da öğretmen görüşlerine göre yetersiz bulunmuştur. Ancak eğitim öğretim sürecinde öğrencilerin yetkinlik düzeylerinin belirlenmesi (Mooij 2007; Shulman 1986, akt. Dijkstra, Walraven, Mooij, \& Kirschner, 2016) ve gidişatın takip edilmesi (Purcell, Burns, Tomlinson, Imbeau, \& Martin, 2002, akt. Dijkstra vd., 2016) son derece önemlidir. Bu bağlamda da MDU'nun geliştirilmesi gerektiği söylenebilir.

Araştırmada elde edilen bir başka sonuç da ÖDM'nin öğrencilerin gelişim alanlarına göre düzeylerini ve geliştirilmesi gereken yönlerini saptamak, ilkokula hazır bulunuşluğunu belirlemek, grubun gerisinde veya ilerisinde olan öğrencileri belirlemek, bu öğrenciler için öğretimi farklılaştırmak, ailelere çocuklarının gelişimleri hakkında nitelikli bilgi vermek için yeterli veri sağladığı ve öğrencilerin gelişim durumlarına ilişkin "süreç değerlendirmesi" yapmak konusunda öğretmen görüşlerine göre yeterli olduğudur. Ancak modelin öğrencilerin ilgi ve yeteneklerini keşfetmek için yeterli veri sağlama konusunda geliştirilmesi gerektiği de tespit edilmiş̧ir. Araştırmada ayrıca öğretmen görüsslerine göre ÖDM'nin en güçlü yönlerinin; bireysel ve gruplar arası değerlendirmeyi sağlama, çocukları daha iyi tanımayı sağlama, öğretmene öz değerlendirme yapma firsatı sağlama, objektif, detaylı ve süreç değerlendirme yapma, öğrencinin geliştirilmesi gereken yönleri hakkında bilgi sağlama ve ölçüm sonrası değerlendirme yapılması olarak belirlenmiştir. Lika (2017)'ya göre de öğrencilerin bilgi düzeyini, öğrenme biçimlerini, seviye ve ilgilerini bilmek gerçekçi, ölçülebilir ve erişilebilir hedefler konması açısından önem taşımaktadır. Ders planlamasının verimliliği için edinilen beceriler ve yetkinlikler önemlidir. Bu açıdan ÖDM ile işletilen sürecin öğretmene öğrencileri hakkında detaylı bilgiler vermesinin önemli bir bulgu olduğu söylenebilir. Çünkü değerlendirme ile elde edilen bilgiler, gelişimin sağlanması ve sürdürülebilmesi için planlamaya temel teşkil eder. ÖDM' nin zayıf yönü ise çocuğun ilgi ve yeteneklerini belirleyebilme konusunda yetersiz kalmasıdır. 
Senemoğlu (1994) eğitim programının, çocuğun bilişsel, çocuğun psikososyal, fiziksel ve devinimsel gelişimlerini de hızlandırabileceğini belirtmiştir. Bunun içinde okul öncesindeki dönemde, ilkokula hazırlayıcı nitelikte beceri ve yeterliklerin geliştirilmesi ihtiyacına dikkat çekmiştir. Bu hususta, ÖDM'nin öğrencilerin Bilişsel Gelişim, Dil Gelişimi, Sosyal ve Duygusal Gelişim, Motor Gelişim ve Öz Bakım Becerileri alanlarının değerlendirmesine olanak sağlamasına karşın sanat, spor vb alanlarda ilgi ve yeteneklerinin belirlenmesi ve/ya değerlendirmesi ile ilgili bir içeriğe sahip olmadığı görülmektedir. Ayrıca, ÖDM öğrencilerin kazanımlara ulaşma durumunu ölçme konusunda da öğretmen görüşlerine göre yeterli/ kısmen yeterli düzeyinde değerlendirilmiştir. Programın etkililiğinin irdelenmesi ve değerlendirilmesi, o program geliştirilmesi için ilk basamağı oluşturur (Özdaş, Tanışlı, Köse, \& K1lıç, 2005). Bu görüşten hareketle, araştırma sonucunda ÖDM ile MDU'da tespit edilen birçok eksiklik ve aksaklığın giderilmiş olduğu söylenebilir. Ayrıca ÖDM'nin öğretmen görüşlerine göre okul öncesi eğitim programının ölçme değerlendirme uygulamaları kapsamında ihtiyaca cevap veren, yeterli bir model olduğu ancak modelin öğrencilerin ilgi ve yeteneklerini keşfetmede yeterli veri sağlama konusunda geliştirilmesi gerektiği belirlenmiştir. 


\section{Extended Summary \\ Introduction}

Significant efforts have been expended to extend the reach of pre-school education in Turkey in recent years. To illustrate, the Ministry of National Education (MoNE) spotted the lack of the prevalence and effectiveness of preschool education opportunities as the weak point and devised strategies oriented to solving this problem (MEB, 2015). Assessment was used as a strategy. Thanks to assessment, which is a crucial element of learning and teaching at any stage of the educational process, weak points could be specified and education could be improved based on the data gathered.

How effectively a program is implemented is crucial. Such pre-school models as PYP, Montessori, High Scope and Regio Emilio are widely used in Turkey. Research bears significance as it has the potential to strengthen the assessment step of the Pre-School Curriculum of the MoNE and disseminate it to all the kindergartens and nurseries implementing it. There are studies in which the pre-school curriculum is analyzed through teachers' opinions. However, an alternative proposal has not been put forward in terms of achieving the desired learning standards. Hence, the aim of the current research is to propose a model to determine the achievement level of learning standards and assess its effectiveness compared to the Current Assessment Model (CAM).

\section{Methodology}

In the realm of qualitative research, a comparative case study design was utilized in the research. The working group comprised of 14 teachers serving at the kindergarten of a private primary school in the center of Gaziantep province in the 2015-2016 Academic Year. There was no teacher with only one year's teaching experience. In the Proposed Assessment Model (PAM), the learning outcomes were determined through the literature survey concerning the developmental characteristics and indicators stated in the MoNE's curriculum and those in international curricula (PYP, Montessori, High Scope and Regio Emilio). In the PAM, teachers form an idea about children's level of achieving the learning outcomes through individual observation, question-answer, demonstration, and anecdotal records during the month. Children's performances are evaluated at the end of the month. Later on, detailed reports are prepared about the assessment of the children's individual and the groups' overall performances. An assessment meeting is conducted with the teachers, administrative and assessment staff. Decisions for improvement are taken and put into effect accordingly. Additionally, the PAM enables feedback to be generated about the effectiveness of the curriculum and teaching methods and techniques.

The research group consisted of 14 teachers at a kindergarten of a private school in the center of Gaziantep province in the 2015-2016 academic year. The data were collected using two different forms entitled "Comparative Assessment Form" and "Teacher Interview Form Regarding Assessment Practices" devised by the researchers. As for the validity and reliability of the forms, the forms were checked by specialist academicians at Gaziantep University and two pre-school teachers. Moreover, a pilot study was conducted with two pre-school teachers. The Comparative Assessment Form consists of eight structured likert-type questions. The participants were asked to compare CAM and PAM in various aspects. The "Teacher Interview Form Regarding Assessment Practices" is semi-structured and includes six open-ended questions about the weak and strong points of the models. A descriptive analysis technique was used for the analysis of the data gathered through the Comparative Assessment Form and the frequencies of teachers' opinions, whereas a content analysis technique was used for those of the Teacher Interview Form Regarding Assessment Practices.

\section{Results}

According to the findings, the CAM is insufficient to conduct formative evaluation specifying children's weak points according to the developmental areas, their readiness level for primary school, the children who are ahead or behind the groups, differentiation of teaching for them, discovering children's interests and abilities and providing enough data to inform parents regarding their children's development. On the other hand, in the light of findings, it could be stated that the PAM satisfies the needs and is sufficient but needs to be improved in terms of providing enough data about children's interests and abilities.

According to the focus group interviews with the teachers, the strongest aspect of the CAM is "providing detailed information" as well as providing objective data, revealing individual differences and including sample forms. 
However, the weakest aspect of the CAM is not being able make detailed evaluation. Then, the strongest aspects of the PAM are to ensure individual and group assessment, helping to know children better, providing teachers with a self-assessment opportunity and conduct formative evaluation in an objective and detailed way, supplying enough data concerning the aspects to be improved and enabling teachers to make evaluations with measurements. What is regarded as the weakest aspect of the PAM is its insufficiency in spotting children's interests and abilities in addition to being an extra workload, interference from children's emotional status in evaluation and planning problems following the evaluation. Finally, the teachers regarded the PAM's effectiveness in measuring children's achievement of learning standards as sufficient or partially sufficient.

\section{Discussion and Conclusion}

According to the teachers' views, the CAM could be said to be weak in various aspects. As assessment is crucial in pre-school (Özsırkıntı, Akay, \& Bolat, 2014), it is necessary that these weaknesses be compensated. However, a limited number of strong aspects have been expressed and providing detailed information is the strongest aspect according to a few teachers. According to Özsırkınt1, Akay and Bolat (2014), detailed and professional assessment is not carried out within the framework of the assessment practices of the 2013 pre-school curriculum. Similarly, this dimension of the curriculum is insufficient according to Durmuşçelebi and Akkaya (2011).

Briefly, the PAM is mostly satisfactory in the ways stated above but needs to be improved in terms of supplying enough data about children's interests and abilities. Lika (2017) stated that knowing children's levels of knowledge, learning styles, levels and interests are of significance to set valid, measurable and accessible goals. Not specifying children's interests and abilities is the weak aspect of the proposed model. To sum up, the PAM satisfies the needs within the scope of the assessment step of the pre-school curriculum and is sufficient but needs to be further developed in some areas. 


\section{Kaynakça / References}

Abdullah, W., Zuhairi, W. M., Zailaini, M. A., \& Jamaluddin, S. (2015). Consideration of the research setting in a qualitative case study: Assessment for learning Arabic language. OIDA International Journal of Sustainable Development, 8(12), 87-94.

Arslan, S., \& İlkay, N. (2015). Okul öncesi öğretim programına yönelik öğretmen görüşleri. Ĕ̆itim Kuram ve Uygulama Araştırmaları Dergisi, 1(1), 22-32.

AMS. (2017). American Montessori Society: What is Montessori. Retrived from: http://www.amshq.org

Aydın, A. (2010). Okul öncesi öğretmenlerinin okul öncesi eğitim programına yönelik değerlendirmeleri (Yayınlanmamış yüksek lisans tezi). Kafkas Üniversitesi, Kars.

Bogdan, R. C., \& Biklen, S. K. (1998). Qualitative research for education: An introduction to theory and methods. Boston: Allyn and Bacon.

Bowling, A. (2002). Research methods in health: Investigating health and health services. Philadelphia: McGraw-Hill House.

Buldu, M. (2010). Do they walk to walk: An examination of Turkish inservice early childhood teachers' assessment practices (Unpublished master thesis). Middle East Technical University, Ankara, Turkey.

Büyüköztürk, Ş., Kılıç-Çakmak, E., Akgün, Ö. A., Karadeniz, Ş., \& Demirel, F. (2008). Bilimsel araştırma yöntemleri (5. baskı). Ankara: Pegem Yayınc1lık.

Charlesworth, R. (1993). Review of professional literarure. The high scope assesment tool, aids education and classroom discipline. Dimensions of Early Childhood, 21, 36-38.

Chmiliar, 1. (2010). Multiple-case designs. In A. J. Mills, G. Eurepas, \& E. Wiebe (Eds.), Encyclopedia of case study research (pp 582-583). Thousand Oaks, CA: SAGE Publications.

Cömert, S. (2003). 2002 Okul Öncesi Ĕ̆itim Programı hakkında öğretmen görüşleri ve uygulamaları (Sakarya Ili Örneği) (Yayınlanmamış yüksek lisans tezi). Sakarya Üniversitesi, Sakarya.

Cró, M. L., Pinho, A. M., \& Andreucci, L. (2012). The High-Scope Curriculum Model in the early childhood education context. Retrived from: http://biblioteca.esec.pt/cdi/ebooks/docentes/L_CRO/CRO_High_Scope_Curriculum.pdf

Çivik, S. P., Ünüvar, P., \& Soylu, B. (2015). Pre-school education teacher's opinion about the implementation of 2013 pre-school education program. Procedia-Social and Behavioral Sciences, 174, 693-698.

Çokluk, Ö., Yılmaz, K., \& Oğuz, E. (2011). Nitel bir görüşme yöntemi: Odak grup görüşmesi. Kuramsal Eğitimbilim, 4(1), 95107.

Demirel, Ö. (2012). Eğitimde program geliştirme kuramdan uygulamaya (19. bask1). Ankara: PegemA.

Dijkstra, E. M., Walraven, A., Mooij, T., \& Kirschner, P. A. (2016). Improving kindergarten teachers' differentiation practices to better anticipate student differences. Educational Studies, 42(4), 357-377.

Durmuşçelebi, M., \& Akkaya, D. (2011). 2006 Okulöncesi Eğitim Programının uygulanmasının öğretmen görüşlerine göre değerlendirilmesi (Kayseri ili örneği). Erciyes Üniversitesi Sosyal Bilimler Enstitüsü Dergisi, 31(2), 255-272.

Düşek, G., \& Dönmez, B. (2012). Türkiye'de yayımlanan okul öncesi eğitim programları. Mesleki Bilimler Dergisi, 1(1), 68-75.

Edwards, C. P. (2002). Three approaches from Europe: Waldorf, Montessori, and Reggio Emilia. Early Childhood Research \& Practice, 4(1), 2-24. Retrived from: http://files.eric.ed.gov/fulltext/ED464766.pdf

Epstein, A. S., Johnson, S., \& Lafferty, P. (2010). The high scope approach. In L. Miller and L. Pound (Eds.), Theories and approaches to learning in the early years (pp. 101-118). London: SAGE.

Ertürk, S. (1998). Eğitimde program geliştirme (10. Baskı). Ankara: Meteksen A.Ş.

Gibbs, A. (1997). “Focus groups”, social research update. Retrived from: http://sru.soc.surrey.ac.uk/SRU19.html 
Georgeson, J., \& Payler, J. (Eds.). (2013). International perspectives on early childhood education and care. UK: McGraw-Hill Education.

Gestwicki, C. (2013). Developmentally appropriate practice: Curriculum and development in early education (5th Ed.). USA: Cengage Learning,

Gülkanat, P. (2015). Okulöncesi öğretmenlerinin Montessori yöntemi ile gerçekleştirilen eğitim uygulamalarına ilişkin görüşlerinin incelenmesi (Yayınlanmamış yüksek lisans tezi). Yeditepe Üniversitesi, İstanbul.

Gündoğdu, K., Turan, S., Kızıltaş, E., Çimen, N., \& Kayserili, T. (2008). 2002 ve 2006 okul öncesi öğretim programlarında yer alan değişikliklerin öğretmen algılarına göre karşılaştırılması. Kazım Karabekir Eğitim Fakültesi Dergisi, $17,47-71$.

Izadpanah, S., \& Günçe, K. (2014). Integration of educational methods and physical settings: Design guidelines for High/Scope methodology in pre-schools. South African Journal of Education, 34(2), 1-17.

Kan, Ü. D. (2007). Okul öncesi eğitimde değerlendirme aracı olarak portfolyo. Gazi Üniversitesi Gazi Eğitim Fakültesi Dergisi, 27(1), 168-179.

Kandır, A., Özbey, S., \& İnal, G. (2010). Okul öncesi öğretmenlerinin öğretim programını planlama ve uygulamada karşılaştıkları güçlüklerin incelenmesi. Uluslararası Sosyal Araştırmalar Dergisi, 2, 6-373.

Kitzinger, J. (1994). The methodology of focus groups: The importance of interaction between research participants. Sociology of Health and Illness, 16(1), 103-121.

Köksal, O., Dağal, A. B., \& Duman, Ö. A. (2016). Okul öncesi öğretmenlerinin okul öncesi eğitim programı hakkındaki görüşlerinin belirlenmesi. International Journal of Social Science, 46(4), 379-394.

Krueger, R. A. (1994). Focus groups: A practical guide for applied research. London: SAGE.

Lika, M. (2017). The impact of curricula and lesson planning in the teaching process. Academic Journal of Business, Administration, Law and Social Sciences, 1(3), 240-247.

MEB. (2013). Okul öncesi ĕgitim programı. Ankara: MEB.

MEB. (2015). Milli ĕgitim istatistikleri. Erişim Adresi: http://sgb.meb.gov.tr/www/mill-egitim-istatistikleri-yayimlanmistir-orgunegitim-2015-2016/icerik/233.

Merriam, S. B. (2009). Qualitative research. A guide to design and implementation (2nd Ed.). San Francisco, CA: Jossey-Bass.

Merriam, S. B., \& Tisdell, E. J. (2015). Qualitative research: A guide to design and implementation (4th Ed.). San Francisco, CA: Jossey-Bass..

Montessori Austarlia. (2010). Montessori approach to assessment and reporting. Retrieved from: https://montessori.org.au/publications/maf-earticle/2010-issue-1

Mooij, T. (2008). Education and self-regulation of learning for gifted pupils: Systemic design and development. Research Papers in Education, 23(1), 1-17.

Nah, K. O., \& Kwak, J. I. (2011). Child assessment in early childhood education and care settings in South Korea. Asian Social Science, 7(6), 66- 78.

Özdaş, A., Tanışlı, D., Köse, N. Y., \& Kılıç, Ç. (2005). Yeni ilköğretim matematik dersi (1.-5. sınıflar) öğretim programının öğretmen görüşlerine dayalı olarak değerlendirilmesi. Eğitimde Yansımalar: VIII Yeni İlköğretim Programlarını Değerlendirme Sempozyumu, 14-16 Kasım, Erciyes Üniversitesi, Kayseri, Türkiye.

Özsırkıntı, D., Akay, C., \& Bolat, E. Y. (2014). Okul öncesi öğretmenlerinin okul öncesi eğitim programı hakkındaki görüşleri (Adana ili örneği). Ahi Evran Üniversitesi Kırşehir Eğitim Fakültesi Dergisi, 15(1), 313- 331.

Purcell, J. H., Burns, D. E., Tomlinson, C. A., Imbeau, M. B., \& Martin, J. L. (2002). Bridging the gap: A tool and technique to analyze and evaluate gifted education curricular units. Gifted Child Quarterly, 46(4), 306-321. 
Roemer, K. L. (1999). Assessment practices used by Montessori teachers of kindergarten through sixth grade students in the united states (Unpublished doctoral dissertation). The University of Memphis, TN, USA.

Roopnarine, J. L., \& Johnson, J. E. (1993). Approaches to early childhood education. New York: Macmillan.

Sağlam, M. (2008). Okul öncesi eğitim programlarının değerlendirilmesi. M. Sağlam (Ed.), Özel öğretim yöntemleri içinde (ss.157-180). Eskişehir: Anadolu Üniversitesi Yayınları.

Sapsağlam, Ö. (2013). Değerlendirme boyutuyla okul öncesi eğitim programları (1952-2013). Uluslararası Türk Eğitim Bilimleri Dergisi, 1, 63-73.

Schweinhart, L. J. (2002). How the High/Scope Perry Preschool study grew: A researcher's tale. Phi Delta Kappa Center for Evaluation, Development, and Research, 32, 1-12.

Senemoğlu, N. (1994). Okulöncesi eğitim programı hangi yeterlikleri kazandırmalıdır. Hacettepe Üniversitesi. Ĕgitim Fakültesi Dergisi, 10, 21-30.

Shulman, L. S. (1986). Those who understand: Knowledge growth in teaching. Educational Researcher, 15(2), 4-14.

Stewart, D. W., \& Shamdasani, P. N. (1990). Focus groups: Theory and practice. Thousand Oaks, CA: SAGE.

Şeker, F. (2012). İlköğretim fen ve teknoloji dersinde tamamlayıcı ölçme ve değerlendirme yaklaşımlarının tutum ve başarıya etkisi (Yayınlanmamış yüksek lisans tezi). Akdeniz Üniversitesi, Antalya.

Şıvgın, N. (2005). Okul öncesi eğitim kurumlarında uygulanan eğitim programına ilişkin öğretmen görüşleri (Denizli ili örneği) (Yayınlanmamış yüksek lisans tezi). Pamukkale Üniversitesi, Denizli.

Topuz, G. Y., \& Kaya, Ö. M. E. (2016). Okulöncesi eğitim öğretmenlerinin çocukları tanıma ve değerlendirme amaçlı yapılan çalışmalara ilişkin görüşleri. Anadolu Üniversitesi Eğitim Bilimleri Enstitüsü Dergisi, 6(1), 27-62.

Yıldırım, A., \& Şimşek, H. (2006). Sosyal bilimlerde nitel araştırma yöntemleri (6. baskı). Ankara: Seçkin. 